\title{
Morbid Obesity in Women is Associated to a Lower Prevalence of Thyroid Nodules
}

\section{Carlo Cappelli, Ilenia Pirola, Francesco Mittempergher, Elvira De Martino, Claudio Casella, Barbara Agosti, Riccardo Nascimbeni, et al.}

\section{Obesity Surgery}

The Journal of Metabolic Surgery and Allied Care

ISSN 0960-8923

Volume 22

Number 3

OBES SURG (2012) 22:460-464

DOI 10.1007/s11695-011-0410-5

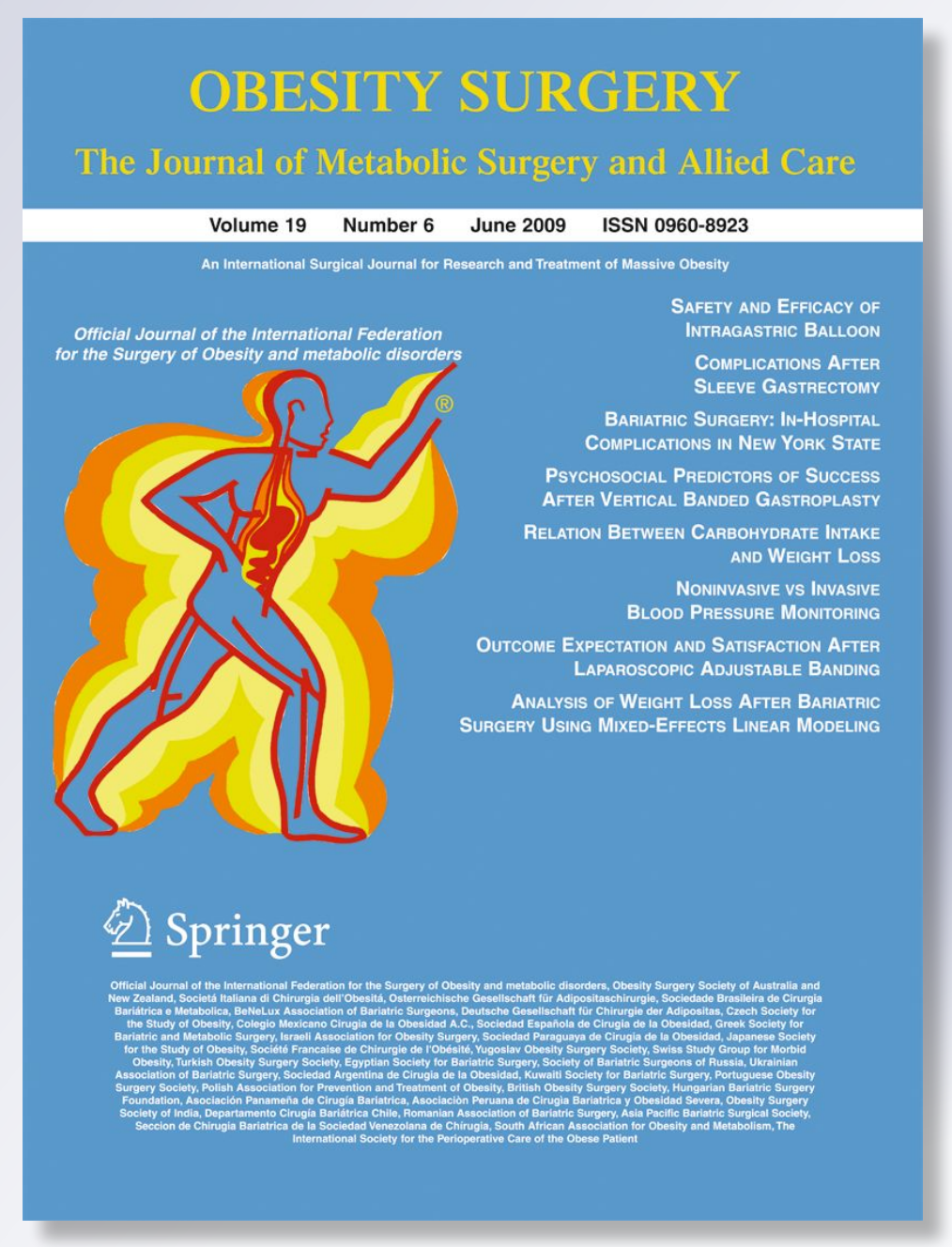

留 Springer 
Your article is protected by copyright and all rights are held exclusively by Springer Science + Business Media, LLC. This e-offprint is for personal use only and shall not be selfarchived in electronic repositories. If you wish to self-archive your work, please use the accepted author's version for posting to your own website or your institution's repository. You may further deposit the accepted author's version on a funder's repository at a funder's request, provided it is not made publicly available until 12 months after publication. 


\title{
Morbid Obesity in Women is Associated to a Lower Prevalence of Thyroid Nodules
}

\author{
Carlo Cappelli • Ilenia Pirola $\cdot$ Francesco Mittempergher • Elvira De Martino • \\ Claudio Casella $\cdot$ Barbara Agosti - Riccardo Nascimbeni - Annamaria Formenti • \\ Enrico Agabiti Rosei • Maurizio Castellano
}

Published online: 14 April 2011

(C) Springer Science+Business Media, LLC 2011

\begin{abstract}
Background Few studies have recently showed functional and morphological changes of the thyroid gland in relation to obesity. To our knowledge, no data are available about the prevalence of thyroid nodules in female obese patients. The aim of this study was to investigate the prevalence of thyroid nodules in morbidly obese women.

Methods One hundred eight consecutive female obese patients were selected from those referred to our medical and surgery outpatients providing that following criteria were satisfied: (1) affected by morbid obesity (body mass index $\left.(\mathrm{BMI})>40 \mathrm{~kg} / \mathrm{m}^{2}\right)$; (2) no previous diagnosis of thyroid disease; (3) biochemically proven euthyroid state at the time of recruitment. Ninety-seven control subjects, constituted by normo-weight and/or slightly overweight $\left(\mathrm{BMI} \leq 30 \mathrm{~kg} / \mathrm{m}^{2}\right)$ women, should satisfy the above criteria 2 and 3. All the subjects were submitted to ultrasound investigation.

Results The two groups of patients displayed no differences for age and fT4 levels. Obese patients clearly showed a lower prevalence of thyroid nodules [odds ratio 0.294, 95\% confidence interval $0.206-0.382$ ]. A single nodule was found in $23 \%$ of obese patients as compared to $65 \%$ of
\end{abstract}

C. Cappelli $(\bowtie) \cdot$ I. Pirola $\cdot$ E. De Martino $\cdot$ B. Agosti $\cdot$

A. Formenti $\cdot$ E. A. Rosei $\cdot$ M. Castellano

Department of Medical and Surgical Sciences,

Endocrine and Metabolic Unit, University of Brescia,

Piazzale Spedali Civili ${ }^{\circ} 1$,

25100 Brescia, Italy

e-mail: cappelli@med.unibs.it

F. Mittempergher $\cdot$ C. Casella $\cdot$ R. Nascimbeni

Department of Medical and Surgical Sciences,

1st Division of General Surgery, University of Brescia,

Brescia, Italy control subjects $(p<0.0001)$. No difference for age (year) was found between obese and non-obese subjects with nodules ( $40.5 \pm 8.2$ vs. $44.2 \pm 8.9$, respectively, $p=0.07$ ).

Conclusions Our data clearly show a significantly lower prevalence of thyroid nodules in morbidly obese patients. Further studies are needed to confirm and to understand this first observation.

Keywords Obesity · Thyroid nodule

\section{Introduction}

Obesity has become a worldwide health problem both in developed and developing countries [1-5]. It has been associated to the increasing incidence of many other chronic diseases, such as diabetes mellitus, hypertension and cardiovascular disease [6].

A potential role for obesity as factor in cancer development, including thyroid cancer, has been reported [7].

It is a common observation that a significant proportion of patients with morbid obesity display slightly increased serum thyroid-stimulating hormone (TSH) levels. However, there is still considerable disagreement as to the physiopathological mechanism responsible for this phenomenon and the clinical significance of this hyperthyrotropinemia [8].

Obesity is associated with structural changes of thyroid morphology, as assessed by ultrasound, which seems to be not related to thyroid autoimmunity both in children than in adults $[9,10]$.

Moreover, previous studies have shown a correlation between thyroid volume and body mass index (BMI), mainly in obese women [11-14]. 
To our knowledge, no data are available about the prevalence of thyroid nodules in obese women. Therefore, in this study, we investigated the prevalence of thyroid nodules in morbidly obese subjects.

\section{Methods and Procedures}

From May 2009 to June 2010, 108 consecutive female obese patients were selected from those referred to our medical and surgery outpatient clinics. Patients were enrolled in the study provided that following criteria were satisfied: (1) affected by morbid obesity (BMI> $\left.40 \mathrm{~kg} / \mathrm{m}^{2}\right)$; (2) no previous diagnosis of thyroid disease; (3) biochemically proven euthyroid state at the time of recruitment.

Ninety-seven controls were selected among patients referred to our division during the campaign for the prevention of thyroid disease (Settimana Nazionale della Tiroide) led by the Associazione Italiana della Tiroide, from 15th to 19th March, 2010.

Control subjects, constituted by normo-weight and/or slightly overweight $\left(\mathrm{BMI} \leq 30 \mathrm{~kg} / \mathrm{m}^{2}\right)$ women, should satisfy the above criteria 2 and 3. BMI was calculated as the weight $(\mathrm{kg})$ measured to the nearest kilogram divided by the square of height determined to the nearest centimetre $(\mathrm{m})$.

All the subjects in the present study were Caucasian, born and living in the greater Brescia area, an endemic zone for goitre [15].

Written informed consent was obtained from all subjects.

\section{Ultrasound}

All the subjects were submitted to ultrasound investigation, which was conducted according to a standard procedure by the same skilled sonographer. Ultrasound investigations were performed using an ultrasonographic scanner (LOGIQ 9, General Electric, Milwaukee, WI, USA) equipped with a 10-14 MHz linear transducer for morphological study. Totally, echo-free nodules were assumed to be cystic nodules and were not considered in this study. The volumes of thyroid glands and thyroid nodules were calculated with the standard formula for an ellipsoid volume.

\section{Serum Assay}

Serum fT4 (normal range: $7.0-18.0 \mathrm{pg} / \mathrm{mL}$ ) and serum TSH (normal range $0.270-4.200 \mathrm{mU} / \mathrm{L}$ ) were determined by microparticle chemiluminescence enzyme immunoassays from Abbott Laboratories (Architect i2000 System ${ }^{\circledR}$, Abbott Park, IL, USA).

\section{Statistical Analysis}

Statistical analysis was performed using the SPSS software version 17 (SPSS, Inc., Chicago, IL, USA).

To compare the case and control groups, the $\chi^{2}$ test was used for categorical variables and an analysis of variance or the Mann-Whitney $U$ test for quantitative variables, as appropriate. A logistic analysis was performed to examine the influence of confounders (age, risk factors) on the prevalence of thyroid nodules.

A $p$ value $<0.05$ was considered statistically significant.

\section{Results}

From May 2009 to June 2010, we recruited 108 patients affected by morbid obesity and 97 control subjects satisfying the assigned criteria for 'cases' and 'controls', respectively.

The clinical and biochemical data of the subjects enrolled in the study subdivided according to their body weight phenotype are reported in Table 1.

The two groups of patients displayed no differences for age and fT4 levels. The obese women showed a significant higher serum TSH levels (mU/L) than control group $(3.4 \pm$ 1.2 vs. $2.1 \pm 1.7, p<0.0001)$.

Among factors potentially associated with the development of thyroid nodules, a positive family history of thyroid disease, defined as the generic occurrence, reported by the subject, of 'thyroid disorders' (not specifically thyroid nodules), was slightly, but not significantly, more frequent in the obese group; smoking and radiation exposure were super-imposable among groups.

At ultrasound evaluation, thyroid gland showed a hypoechoic feature more frequent in obese than in nonobese subjects ( $76.4 \%$ vs. $15.7 \%$, respectively, $p<0.0001)$.

Table 1 Clinical and biochemical data of the subjects enrolled in the study

\begin{tabular}{llll}
\hline & $\begin{array}{l}\text { Morbidly obese } \\
\text { patients }\end{array}$ & Controls & $P$ value \\
\hline Number of cases & 108 & 97 & \\
Age (years) & $40.2 \pm 7.0$ & $41.4 \pm 11.2$ & NS \\
BMI (Kg/m $\left.{ }^{2}\right)$ & $44.6 \pm 2.8$ & $27.0 \pm 2.4$ & $<0.0001$ \\
Smokers (\%) & 9.1 & 10.5 & NS \\
Family history of thyroid & 11.4 & 8.2 & NS \\
$\quad$ disease (\%) & & & \\
Radiation exposure (\%) & 0 & 0.9 & NS \\
TSH (mU/L) & $3.3 \pm 1.2$ & $2.1 \pm 1.6$ & $<0.0001$ \\
fT4 (pg/mL) & $14.2 \pm 4.1$ & $14.6 \pm 4.2$ & NS \\
\hline
\end{tabular}


The prevalence and size of thyroid nodules, as well as, the thyroid size in the two groups are reported in Table 2, whereas the ultrasound characteristics of thyroid nodules are reported in Table 3.

Obese patients clearly showed a lower prevalence of thyroid nodules [odds ratio $0.294,95 \%$ confidence interval 0.206-0.382], but with a significant larger volume ( $\mathrm{ml})$ of lesions, as compared to the control group $(0.9 \pm 1.6$ vs. $0.4 \pm$ $0.4, p=0.004$ ). No difference for age (year) was found between obese and non-obese subjects with nodules (40.5 \pm 8.2 vs. $44.2 \pm 8.9$, respectively, $p=0.07$ ).

A single nodule was found in $23 \%$ of obese patients as compared to $65 \%$ of control subjects, demonstrating a statistical difference between the two groups $(p<0.0001)$.

Nodules showed similar ultrasound characteristics (in terms of echogenecity, margins, calcification, and vascularity) between the two groups of subjects.

Thyroid volume was significantly larger in the obese group than in control one, even after adjustment by individual BMI and TSH values $(20.1 \pm 5.0$ vs. $18.2 \pm 5.5$, respectively, $p=0.005$ ).

Nodule(s) volume remained larger in these obese women even after correction by the respective thyroid volume.

\section{Discussion}

The results of our study show that morbidly obese women have significantly lower prevalence and lower number of solid thyroid nodules.

Overall, there was a marked tendency for thyroid gland to develop nodular lesions; namely, in cases of areas of endemic goitre, from which both obese and controls women of the present study were selected. Therefore, the very high prevalence of thyroid nodules in the controls group is not surprising and in agreement with findings reported by ultrasound investigation performed in popula-

Table 2 Thyroid size, prevalence, and size of thyroid nodules

\begin{tabular}{llll}
\hline & $\begin{array}{l}\text { Morbidly obese } \\
\text { patients }\end{array}$ & Controls & $P$ value \\
\hline $\begin{array}{l}\text { Thyroid volume (ml) } \\
\begin{array}{l}\text { Prevalence of nodules } \\
(\%)\end{array}\end{array}$ & $20.1 \pm 5.0$ & $18.2 \pm 5.5$ & 0.005 \\
$\begin{array}{l}\text { Multiple nodules (\%) } \\
\text { Nodules per subjects }\end{array}$ & 4.6 & 71.1 & $<0.0001$ \\
$\begin{array}{l}\text { Nodule Volume (ml) } \\
\text { Nodule volume/Thyroid } \\
\text { volume (\%) }\end{array}$ & $0.3 \pm 0.5$ & 6.2 & $\mathrm{NS}$ \\
$\begin{array}{l}\text { Nodule size range (mm) } \\
\text { Nol.2 }\end{array}$ & $0.4-3.1$ & $0.8 \pm 0.7$ & $<0.0001$ \\
\hline
\end{tabular}

Table 3 Ultrasound findings in thyroid nodules

\begin{tabular}{lcll}
\hline US features & $\begin{array}{l}\text { Nodules in morbidly } \\
\text { obese patients (\%) }\end{array}$ & $\begin{array}{l}\text { Nodules in } \\
\text { controls (\%) }\end{array}$ & $\begin{array}{l}P \\
\text { value }\end{array}$ \\
\hline Hyperchoic & $5 / 35(15.7)$ & $11 / 81(13.6)$ & NS \\
Isoechoic & $11 / 35(30.1)$ & $21 / 81(25.9)$ & NS \\
Hypoechoic & $19 / 35(55.2)$ & $43 / 81(53.1)$ & NS \\
Calcification present & $10 / 35(28.7)$ & $22 / 81(27.2)$ & NS \\
Blurred Margins & $6 / 35(17.7)$ & $11 / 81(13.6)$ & NS \\
Intranodular vascularity & $16 / 35(45.6)$ & $35 / 81(43.2)$ & NS \\
\hline
\end{tabular}

tion with similar characteristics $[16,17]$ and with our previous report [18].

Few studies have investigated functional and morphological changes of the thyroid gland in relation to obesity and/or metabolic syndrome [16, 19-23]. In agreement with literature data, we showed a significant higher serum TSH levels in obese patients compared to control group. There is still considerable disagreement as to the physiopathological mechanism responsible for this phenomenon.

Some authors have suggested that hormonal mediators from adipose tissue could stimulate the hypothalamous-pituitary-thyroid axis in order to increase TSH secretion $[19,24]$; the main suspected is leptin, which seems to up-regulate TRH expression [25], but the clinical significance of this hyperthyrotropinemia is still a matter of discussion [8].

Structural changes of thyroid morphology not related to thyroid autoimmunity have recently been described in morbid obesity. Our data confirm a recent study obtained in children, which showed hypoechoic thyroid structure more frequent in obese patients than those observed in normo-weight and/or slightly overweight subjects [9]. More recently, we evidenced the same ultrasound feature in adults [10].

To our knowledge, there are no explanations to this observation. A hypothesis could be that patients with an extreme weight excess may have the tendency to accumulate fat in the thyroid. However, Radetti et al. evidenced only colloid drops and thyrocytes and not adipose cells in thyroid cytological samples [9], making unlikely the previous assumption.

Another intriguing hypothesis could be that the excess of subcutaneous fat layer in the neck may interfere with the normal acoustic impedance on ultrasound examination, causing a reduction of frequency acoustic waves to be reflected back to the probe. Nevertheless, we did not see any correlation between thyroid ultrasound echogenicity and subcutaneous fat thickness (data not shown). A positive correlation between thyroid volume and body weight or BMI has been observed [11-14, 16], but, to our knowledge, 
no previous studies have investigated the prevalence of thyroid nodules in morbidly obese women.

We clearly show a significantly lower prevalence and lower number of solid thyroid nodules in these patients than those observed in normo-weight and/or slightly overweight subjects. However, the great difference of thyroid nodules between the two groups of women is considerable and raises the crucial issue of the possible presence of bias or confounders. We reasonably excluded the possibility that characteristics such as age and other risk factors, known to be associated with thyroid nodules, may have influenced our results. Although we have no data on iodine excretion in the two groups, it is highly unlikely that this could be significantly different among them because all subjects in both groups were born and were still living in the same mild iodine deficiency area and had similar dietary behaviour. Moreover, our results would seem to be opposite to what would have been expected, basing upon reports showing greater thyroid nodule prevalence in association with the metabolic syndrome and insulin resistance. However, it is fairly well established that the incidence of insulin resistance and the metabolic syndrome, in general, is greater among individuals with morbid obesity than for their non-obese counterparts [11-16]. Unfortunately, we have no data about insulin serum levels in our morbidly obese patients. Anyway, clinical and genetic evidence supports the concept that obesity does not represent a continuous entity and that obese patients with BMI lower or higher than $40 \mathrm{Kg} / \mathrm{m}^{2}$ are likely to harbour a different disease [26]. For this reason, obese and morbidly obese patients could show different thyroid phenotypes, even if at this time we have not proven any argument to explain our results.

A potential role, for obesity as factor in cancer development including thyroid cancer, has been reported [7]. A recent study by Boru et al. clearly showed a significant association between morbidly obese women attending bariatric surgery and malignancy, in particular thyroid cancer [27]. The cytological or histological ascertainment of thyroid nodules was not considered in the protocol of this study and only few subjects were submitted to fine needle aspiration cytology of their nodules. Therefore, no data are available concerning the possible occurrence of neoplastic lesions.

In conclusion, our data clearly show a significantly lower prevalence of thyroid nodules in morbidly obese women. Further studies are needed to confirm and to understand this first observation.

Conflict of Interest Disclosure All the authors declare that they have no conflict of interest.

\section{References}

1. Wang Y, Chen H, Shaikh S, et al. Is obesity becoming a public health problem in India? Examine the shift from under-to overnutrition problems over time. Obes Rev. 2009;10:456-74.

2. Popkin BM, Doak CM. The obesity epidemic is a worldwide phenomenon. Nutr Rev. 1998;56:106-14.

3. Wang Y, Mi J, Shan XY, et al. Is China facing an obesity epidemic and the consequences? The trends in obesity and chronic disease in China. In J Obes. 2007;31:177-88.

4. Wang Y, Lobstein T. Worldwide trends in childhood overweight and obesity. In J Pediatr Obes. 2006;1:11-25.

5. Martorell R, Khan LK, Hughes ML, et al. Obesity in women from developing countries. Eur J Clin Nutr. 2000;54:247-52.

6. Flegal KM, Carroll MD, Ogden CL, et al. Prevalence and trends in obesity among US adults 1999-2000. JAMA. 2002;288:17237.

7. Renehan AG, Tyson M, Egger M, et al. Body-mass index and incidence of cancer: a systematic review and meta-analysis of prospective observational studies. Lancet. 2008;16:536-7.

8. Reinehr T. Obesity and thyroid function. Mol Cell Endocrinol. 2010;316:165-71.

9. Radetti G, Kleon W, Buzi F, et al. Thyroid function and structure are affected in childhood obesity. J Clin Endocrinol Metab. 2008;93:4749-54.

10. Rotondi M, Cappelli C, Leporati P, et al. A hypoechoic pattern of the thyroid at ultrasound does not indicate autoimmune thyroid diseases in patients with morbid obesity. Eur $\mathrm{J}$ Endocrinol. 2010;163:105-9.

11. Rezzonico J, Rezzonico M, Pusiol E, et al. Introducing the thyroid gland as another victim of the insulin resistance syndrome. Thyroid. 2008;18:461-4.

12. Paes JE, Hua K, Nagy R, et al. The relationship between body mass index and thyroid cancer pathology features and outcomes: a clinicopathological cohort study. J Clin Endocrinol Metab. 2010;95:4244-50.

13. Wesche MF, Wiersinga WM, Smits NJ. Lean body mass as a determinant of thyroid size. Clin Endocrinol. 1998;48:701-6.

14. Gómez JM, Maravall FJ, Gómez N, et al. Determinants of thyroid volume as measured by ultrasonography in healthy adults randomly selected. Clin Endocrinol. 2000;53:629-34.

15. Cappelli C, Agosti B, Tironi A, et al. Prevalence and aggressiveness of thyroid carcinoma with diameter less than one centimetre in iodine deficiency areas. Minerva Endocrinol. 2002;27:65-71.

16. Ayturk S, Gursoy A, Kut A, et al. Metabolic syndrome and its components are associated with increased thyroid volume and nodule prevalence in a mild-to-moderate iodine-deficient area. Eur J Endocrinol. 2009;161:599-5.

17. Rasmussen LB, Ovesen L, Bülow I, et al. Relations between various measures of iodine intake and thyroid volume, thyroid nodularity, and serum thyroglobulin. Am J Clin Nutr. 2002;76:1069-6.

18. Cappelli C, Castellano M, Pirola I, et al. Reduced thyroid volume and nodularity in dyslipidaemic patients on statin treatment. Clin Endocrinol. 2008;68:16-21.

19. Sari R, Balci MK, Altunbas H, et al. The effect of body weight and weight loss on thyroid volume and function in obese women. Clin Endocrinol. 2003;59:258-62.

20. Michalaki MA, Vagenakis AG, Leonardou AS, et al. Thyroid function in humans with morbid obesity. Thyroid. 2006;16:738.

21. De Pergola G, Ciampolillo A, Paolotti S, et al. Free triiodothyronine and thyroid stimulating hormone are directly associated with waist circumference, independently of insulin resistance, metabolic parameters and blood pressure in overweight and obese women. Clin Endocrinol. 2007;67:265-9. 
22. Knudsen N, Laurberg P, Rasmussen LB, et al. Small differences in thyroid function may be important for body mass index and the occurrence of obesity in the population. J Clin Endocrinol Metab. 2005;90:4019-24.

23. Ruhla S, Weickert MO, Arafat AM, et al. A high normal TSH is associated with the metabolic syndrome. Clin Endocrinol. 2010;72:696-1.

24. Rosenbaum M, Hirsch J, Murphy E, et al. Effects of changes in body weight on carbohydrate metabolism, catecholamine excretion, and thyroid function. Am J Clin Nutr. 2000;71:142132.

25. Zimmermann-Belsing T, Brabant G, Holst JJ, et al. Circulating leptin and thyroid dysfunction. Eur J Endocrinol. 2003;149:257-71.

26. Rotondi M, Magri F, Chiovato L. Thyroid and obesity: not a oneway interaction. J Clin Endocrinol Metab. 2011;96:344-6.

27. Boru C, Silecchia G, Pecchia A, et al. Prevalence of cancer in Italian obese patients referred for bariatric surgery. Obes Surg. 2005;15(8):151171-6. 